\title{
Reactive Hyperplastic Lesions of Oral Cavity: A Review of Literature
}

\author{
Bhagyashree M Nair ${ }^{1}$, Sowbhagya Malligere Basavaraju², Balaji Pachipulusu ${ }^{3}$
}

\begin{abstract}
Oral mucosa has the potential to give rise to reactive lesions that are non-neoplastic in nature. A wide variety of lesions differing from developmental to neoplastic type can be elicited. Lesions that arise in response to chronic irritation to the oral mucosa are referred to as reactive lesions. Agents like calculus, sharp cuspal tips, overhanging dental restorations, masochistic habits, ill-fitting prosthesis and appliances, and food impactions are the most common etiological factors. These lesions simulate each other in their clinical behavior. Therefore, it is of utmost importance to clinically correlate these lesions with histopathological features to avoid misdiagnosis of the conditions. The most commonly found lesions are traumatic fibroma (TF), pyogenic granuloma (PG), epulis fissuratum (EF), peripheral giant cell granuloma (PGCG).

Keywords: Epulis fissuratum, Peripheral giant cell granuloma, Pyogenic granuloma, Traumatic fibroma.

Journal of Health Sciences \& Research (2019): 10.5005/jp-journals-10042-1085
\end{abstract}

\section{INTRODUCTION}

Oral cavity is constantly being exposed to many stimuli which can irritate the oral mucosa leading to a variety of hyperplastic reactions. Reactive hyperplastic lesions (also called RHLs) are tumorlike hyperplasia produced in response to chronic irritation or trauma. These hyperplastic lesions simulate non-neoplastic proliferations. The goal for the treatment of these conditions is the elimination of the stimulating agents followed by proper dental therapy. Clinically, the reactive lesions can be classified as traumatic fibroma (TF), pyogenic granuloma (PG), PT, and epulis fissuratum (EF). The histologic classification of RHL is angiomatous hyperplasia $(\mathrm{AH})$, fibrous hyperplasia $(\mathrm{FH})$, peripheral ossifying fibroma (POF), and peripheral giant cell granuloma (PGCG). The most common reactive hyperplastic lesions that are encountered in the day-to-day clinical practice are as follows: traumatic fibroma (TF), pyogenic granuloma (PG), pregnancy tumor (PT), peripheral giant cell granuloma, and epulis fissuratum (EF). All these lesions intermingle with each other in their clinical appearances, but the final diagnosis depends on their histopathological features. According to Eversole and Rovin, the different histological entities of inflammatory hyperplasias may be due to the response of connective tissue to varying intensities of mucosal irritation, which is very similar to neoplastic proliferation. The clinical behavior of RHLs pose a challenge in the differential diagnosis of the lesions, as it may vary in different population depending on the variations in the environmental factors and lifestyles. ${ }^{1-3}$ This paper explains the distinguishing clinical and histopathological features and the management of some of most commonly encountered reactive hyperplastic lesions.

\section{Pyogenic Granuloma}

\section{Introduction}

Pyogenic granuloma, also known as acquired lobular capillary hemangioma, is a solitary benign vascular tumor of the skin or mucosa. It commonly affects children and young adults, sometimes pregnant women and rarely elderly individuals. ${ }^{4}$

\footnotetext{
${ }^{1-3}$ Department of Oral Medicine and Radiology, RajaRajeswari Dental College and Hospital, Bengaluru, Karnataka, India

Corresponding Author: Balaji Pachipulusu, Department of Oral Medicine and Radiology, RajaRajeswari Dental College and Hospital, Bengaluru, Karnataka, India, Phone: +91 9448762432, e-mail: drbalaji_24@rediffmail.com

How to cite this article: Nair BM, Basavaraju SM, Pachipulusu B. Reactive Hyperplastic Lesions of Oral Cavity: A Review of Literature. J Health Sci Res 2019;10(2):42-46.

Source of support: Nil

Conflict of interest: None
}

\section{Synonyms}

Pyogenic granuloma is also known as granuloma pediculatum benignum, benign vascular tumor, pregnancy tumor, vascular epulis, and Crocker and Hartzell's disease.

\section{Historical Background}

- Poncet and Dor first introduced the term "pyogenic granuloma" in 1897. It was called botryomycosis hominis.

- The term "pyogenic granuloma" was introduced by Hartzell in 1904.

- Due to the enormous neovascularization, it is also called granuloma telangiectacticum.

- It is a "benign, acquired, vascular, neoplasm.."2,4-6

\section{Etiopathogenesis}

Various etiopathogenesis have been postulated about pyogenic granuloma.

- Minor trauma to the tissues provides a pathway for invasion of nonspecific types of microorganisms which causes overzealous proliferation of a vascular type of connective tissue.

- The granulation tissue in oral pyogenic granuloma becomes contaminated by the flora of oral cavity covering the surface by fibrin mimicking pus.

() The Author(s). 2019 Open Access This article is distributed under the terms of the Creative Commons Attribution 4.0 International License (https://creativecommons. org/licenses/by-nc/4.0/), which permits unrestricted use, distribution, and non-commercial reproduction in any medium, provided you give appropriate credit to the original author(s) and the source, provide a link to the Creative Commons license, and indicate if changes were made. The Creative Commons Public Domain Dedication waiver (http://creativecommons.org/publicdomain/zero/1.0/) applies to the data made available in this article, unless otherwise stated. 
- Factors like trauma, primary tooth injuries, chronic irritation, hormones, drugs, gingival inflammation, chronic irritation due to exfoliation of primary teeth, defective fillings in the region of tumor, food impaction, and toothbrush trauma contribute toward the development of the lesion.

- Cytokines like bFGF, which is a heparin binding angiogenic protein, is found to be highly mitogenic for capillary endothelial cells thereby inducing angiogenesis.

- Hormonal influence in females triggers the formation of pg as estrogen and progesterone acts on gingiva as the target organ.

- Vascular morphogenesis factors like angiopoietin-1, angiopoietin-2, ephrinb2, and ephrinb4 are upregulated in pyogenic granuloma. $^{4-7}$

\section{Clinical Features}

Oral pyogenic granuloma has an increased predilection for females in the second to fifth decades of life. It is found most commonly on the gingiva followed by the lips, tongue, buccal mucosa, and hard plate. Less commonly involved sites are palate, mucobuccal fold, and the frenum. PG presents an array of clinical appearances presenting from a sessile mass to an elevated lesion. They appear as soft, painless, and deep red to reddish-purple nodules which are characteristically ulcerated depending upon the chronicity of the lesion.

Another distinguishing terminology is the occurrence of pyogenic granuloma in pregnant women, which is referred to as pregnancy tumor or pyogenic gravidarium. It develops in the third trimester and may extend till the seventh month of pregnancy. The development of the lesion during pregnancy is due to the elevated levels of estrogen. The pyogenic granuloma presents as a solitary lesion. Satellite lesions do not multiply commonly. Appearance of new lesions around the site of recently treated lesions is an indication of recurrence. ${ }^{2,7}$

\section{Differential Diagnosis}

Peripheral giant cell granuloma, POF, fibroma, peripheral odontogenic fibroma, hemangioma, conventional granulation tissue, hyperplastic gingival inflammation, Kaposi's sarcoma, bacillary angiomatosis, angiosarcoma, and non-Hodgkin's lymphoma. ${ }^{4,6,8,9}$

\section{Histology}

The histological appearance of pyogenic granuloma is distinguishing in nature. The lesion has characteristic appearances like (i) the cellular phase, (ii) capillary phase/vascular phase, and (iii) involutionary phase.

Pyogenic granuloma is also of two types, namely, lobular capillary hemangioma ( $\mathrm{LCH})$ and nonlobular capillary hemangioma (non-LCH).

Numerous endothelium-lined vascular spaces with neoangiogenesis endothelial proliferation with inflammatory cell infiltrates are the characteristic features of pyogenic granuloma. Lobular aggregates of proliferating blood vessels is the feature of Ich whereas the non-Ich type has high vascular proliferation resembling granulation tissue. ${ }^{2,3,9}$

\section{Management}

The treatment modalities for PG includes excisional surgery, $\mathrm{Nd}$ :YAG laser, flash lamp pulsed dye laser, cryosurgery, intralesional injection of ethanol or a corticosteroid, and sodium tetradecyl sulfate sclerotherapy.

- The most commonly used technique is surgical excision of the lesion with wide and negative margins. However, incomplete excision results in recurrence of the lesion and also increased postoperative pain and edema.

- Lasers are the newer techniques available with the advantages of minimal intra and postoperative bleeding and pain; moreover esthetic benefits are higher.

- Cryosurgery electric scalpel helps in the complete resolution of PG.

- Local injection of ethanol is an alternative therapy for PG.

- Corticosteroids increases the response of the lesion in the vascular bed to vasoconstricting agents.

- Sclerosing agents used in management includes intralesional injection of $3 \%$ sodium tetradecyl/sulfate.

- The advantages of this procedure are minimal discomfort to the patient, no or less blood loss, less technique sensitive, and above all is economical.

- Local anesthesia or postoperative dressing is not required or any specific care. ${ }^{9,10}$

\section{Traumatic Fibroma}

\section{Introduction}

Fibroma is a benign neoplasm of fibroblastic origin. It is reactive in nature and is a hyperplasia of fibrous connective tissue in response to local irritation. Fibroma is the healed end product of the inflammatory hyperplastic lesion which may occur at any age from any soft-tissue site, tongue, gingiva, and buccal mucosa being the most common., ${ }^{1,2,11}$

\section{Synonyms}

Fibroma, focal fibrous hyperplasia, peripheral fibroma, peripheral ossifying fibroma fibroid epulis (old term), fibroepithelial polyp.

\section{History}

Fibroma is a rare intraoral benign neoplasm of fibroblastic origin. Fibromas of oral cavity are reactive hyperplasia of fibrous connective tissue in response to irritants.

- Contradictions exist regarding the presence of true benign neoplasm composed of fibroblasts.

- The histological criteria of a true fibroma were proposed by Barker and Lucas. ${ }^{12,13}$

\section{Etiology}

Irritational fibroma, as the name suggests, has an etiology, that is, a source of irritation. Common irritants are fractured or sharp restorations, sharp cuspal tips, ill-fitting prosthesis, and food impactions.

\section{Clinical Features}

The most common location is the buccal mucosa along the occlusal plane. Continuous irritation can result in hyperkeratosis giving it a white appearance. It is also found on the labial mucosa, tongue, and gingiva. ${ }^{14}$ Most fibromas are sessile, but some are pedunculated though. The lesion typically appears as a smooth surfaced pink nodule simulating the mucosa which may vary on racial discrimination. The size of the fibroma ranges from a few 
millimeters to not more than $1.5 \mathrm{~cm}$. Irritation fibromas are usually asymptomatic, unless secondarily ulcerated. Being common in the fourth to sixth decades of life, there is a slightly higher predilection for females.

\section{Differential Diagnosis}

Hyperplastic fibroma, peripheral giant cell granuloma, peripheral ossifying fibroma, and pyogenic granuloma. ${ }^{2,12}$

\section{Histology}

The pattern of arrangement of collagen bundles is unique. A radiating and circular pattern of collagen bundles can be seen. However, it has been hypothesized from various studies that, in areas of a greater degree of trauma, a radiating pattern of collagens is seen whereas in minor traumatic areas a circular pattern is observed. ${ }^{2,3,11}$

\section{Management}

Like any other reactive lesion, traumatic fibroma also has multiple treatment modalities which include both surgical and nonsurgical techniques.

Scalpel Surgery: Surgical enucleation with a scalpel is the most widely used form of treatment, which is the complete removal of the lesion with safety margins during the surgical procedure. The drawbacks of conventional scalpel surgery include intraoperative bleeding management, the need for suturing, and the risk of postoperative edema.

Electrosurgery is an invasive procedure due to the excessive generation of heat with the potential for scarring.

Cryosurgery is the use of liquid nitrogen to destroy tissue by rapid freezing. It is a time-consuming procedure and is contraindicated in patients with cold intolerance.

Soft-tissue diode near-infrared laser light circa $1,000 \mathrm{~nm}$ is not used to optically ablate the oral soft tissue. The diode laser optical energy is used exclusively to heat up the charred distal end of the fiberglass tip to $500^{\circ} \mathrm{C}$.

The removal of an irritation fibroma can be most efficiently performed with the $\mathrm{CO}_{2}$ laser because of its inherent advantages, of hemostasis, diminished postoperative edema, uneventful healing, and decreased scarring

The Nd:YAG laser of 1,064-nm wavelength is an efficient coagulator but a poor scalpel, as it is highly scattered and weakly absorbed by the soft tissue.

To enhance its cutting efficiency, the low absorption of the $\mathrm{Nd}$ :YAG wavelength is attenuated by the use of very high peak power. ${ }^{11-13}$

\section{Epulis Fissuratum Introduction}

A poorly fitted prosthesis gives rise to a variety of problems like pain, discomfort in mastication, and speech. Epulis fissuratum refers to reactive tissue response to excessive mechanical pressure from an ill-fitting prosthesis.

\section{Synonyms}

Inflammatory fibrous hyperplasia, denture-induced fibrous inflammatory hyperplasia, denture injury tumor, denture epulis, denture induced granuloma, granuloma fissuratum. ${ }^{2,15}$

\section{Background}

Virchoff introduced the term 'epulis' meaning 'over the gums'. Later it was replaced by 'denture induced hyperplasia' based on the prevalence of occurrence of the lesion on the vestibular sulcus than the gingiva. Denture-induced fibrous hyperplasia is an adaptive growth caused by chronic irritation.

\section{Clinical Features}

Three types of EF are present, namely, fibromatous, acanthomatous and ossifying.

EF appears as single or multiple folds of hyperplastic tissue on the alveolar mucosa which is usually firm and fibrous on palpation. It can also be erythematous and ulcerated if secondarily infected, thereby mimicking pyogenic granuloma. The size of the lesion usually varies between a few millimeters to more than $1 \mathrm{~cm}$. There has been an increased predilection in elderly females with more occurrence on the anterior portion of oral cavity.

\section{Histology}

The overlying epithelium is hyperparakeratotic with hyperplasia of the rete ridges. The epithelium shows inflammatory papillary hyperplasia. Focal areas of ulceration are not unusual, especially at the base of the grooves between the folds. A variable chronic inflammatory infiltrate is also present. ${ }^{15-17}$

\section{Differential Diagnosis}

Pyogenic granuloma, neurofibroma, and very rarely in severe cases squamous cell carcinoma is also be considered..$^{2,15}$

\section{Management}

Treatment of Epulis fissuratum includes both conservative and surgical conservative method includes the removal of the acrylic flange followed by relining and rebasing after the complete healing of the lesion.

- The surgical approach includes the use of conventional scalpel, electrocauterization, soft tissue lasers, and liquid nitrogen cryosurgery.

- Electrocauterization is another method used to remove Epulis fissuratum with the advantages of hemorrhage control and better postoperative healing.

- The commonly used lasers are $\mathrm{CO}_{2}$ laser, Er:YAG laser, $\mathrm{Nd}$ :YAG laser, diode laser, argon laser, and KTP laser.

- Better and uneventful healing is observed with carbon dioxide laser than with the surgical scalpel between postoperative days 7 and 14

- The advantages of the laser therapy are specificity, asepticity, minimal postoperative pain and edema, rapid wound healing, minimal recurrence rate, repeatability of the treatment, and minimal functional impairment in the oral cavity.

- Liquid nitrogen cryosurgery is used because of the better hemorrhage control and postoperative healing.

- Another advantage is that cryosurgery is a painless procedure because of the immediate blockage of the nerve transmission in that area. It achieves homeostasis by means of necrosing the capillary ends. Moreover, it is economical when compared with its counterpart techniques. Hence all these properties of cryosurgery make it a best suited technique in treating geriatric patients. ${ }^{17-19}$ 


\section{Peripheral Giant Cell Granuloma}

\section{Introduction}

PGCG is a common non-neoplastic reactive hyperplastic lesion of the oral cavity which is defined and demarcated by its varied histological appearances. PGCG is a relatively common lesion. However, the etiology, growth potential, biological behavior, histogenesis of its cells and its treatment have always been ambiguous. The lesion is known for its notorious behavior and its high recurrence rate.

\section{Synonyms}

Giant cell epulis, peripheral giant cell tumor, and reparative giant cell granuloma. $2,3,19,20$

\section{Historical Background}

PGCG could be either peripheral or central giant cell reparative granuloma. Giant cell granulomas occurring within the bone are called central giant cell granuloma (CGCG) and those occurring on edentulous alveolar processes or gingivae are called PGCG.

\section{Etiopathogenesis}

The most common predisposing factor is the presence of local irritants and poor oral hygiene. The lesion arises from the periodontal ligament membrane. The periodontal ligament responds intensely to the local irritants which is severe with PGCG than any other reactive lesions.

- Chronic irritants like improper restorations, food impaction, and calculus are the common causative agents.

- Extractions: Post-extraction healing sockets are also one of the instigating agents of the lesion.

- Xerostomia: Decreased salivary flow leads to alteration in physiological functions of saliva exposing the oral mucosa to constant irritation, which inadvertently leads to hyperplastic lesion.

- Hormonal influence: PGCG is pregnancy mediated rather than being "pregnancy dependent." It is due to the immunosuppressive action of hormones along with hyper responsiveness of the gingiva to these hormones..$^{14,21}$

\section{Clinical Features}

PGCG occurs in any age. It is more prevalent in females of fourth to sixth decades of life. Mandible is more prevalent than maxilla. It appears as painless, soft, nodular mass, usually red to reddish-blue in color. The typical bluish red hue is the characteristic of the PGCG. A secondarily infected lesion has a 'yellow zone' caused due to the aggregation of a fibrin clot at the ulcer site.

The size of the lesion ranges from papules to lesions more than $40 \mathrm{~mm}$. The chronicity of the irritants also determines the size of the lesions. Compromised oral health and hygiene, ill-fitting dentures, and xerostomia are the common triggering factors. ${ }^{19}$

\section{Histopathology}

PGCG has a characteristic histopathological appearance. Numerous multinucleated giant cells with proliferating fibroblasts in fibrocellular stroma are the hallmark of the lesion. The fibroblasts appear plumpy spindles whereas the giant cells are multimorphological. Two types of giant cells are present, namely, type I and type II wherein type I cells are more numerous than type II.

\section{Differential Diagnosis}

Pyogenic granuloma, hemangioma, CGCG, POF and metastatic carcinomas.

\section{Management}

The treatment of PGCG includes excision of the growth down to the periosteum with scalpel, electrocautery, or lasers and also eliminating any local irritating factors associated with it.

Lasers are a good option to perform excision as they provide excellent hemostasis, bactericidal effect, precision, short healing time, better postoperative pain perception, and less discomfort to the patient. ${ }^{14,21,22}$

\section{Recurrence and Prognosis}

The prognosis of reactive hyperplastic lesions depends upon the accuracy of elimination of the etiological factors and the type of treatment modality. However, from the previous studies, it is being interpreted that the recurrence rate varies between 2 and $28 \%$ with increased prevalence for pyogenic granuloma and least for peripheral giant cell granuloma. ${ }^{1,23,24}$

\section{Conclusion}

Hence we may conclude that reactive lesions of oral cavity has varying clinical appearances which may simulate multiple lesions. However, a complete clinical examination correlated with the histopathological features is required for the proper diagnosis. Moreover, the choice of the treatment modality also contributes to the prognosis of the lesion.

\section{References}

1. Naderi NJ, Eshghyar N, Esfehanian H. Reactive lesions of the oral cavity: a retrospective study on 2068 cases. Dent Res J (Isfahan) 2012;9(3):251-255

2. Neville BW, Damm DD, Allen CM, et al. Soft tissue tumors. In: Neville BW, Damm DD, Allen CM, et al., ed., Oral and Maxillofacial Pathology. 4th ed., Philadelphia, Pa, USA: WB Saunders; 2015. p. 485.

3. Shafer H, Levi. Shafer's Textbook of Oral Pathology. 7th ed., 2012.

4. Kamal R, Dahiya P, Puri A. Oral pyogenic granuloma: various concepts of etiopathogenesis. J Oral Maxillofac Pathol 2012;16(1):79-82. DOI: 10.4103/0973-029X.92978.

5. Patil SR, Maheshwari S, Khandelwal S, et al. Prevalence of reactive hyperplastic lesions of the gingiva in the Western Indian population J Orofac Sci 2014(1):641-645. DOI: 10.4103/0975-8844.132585.

6. Sharma S, Chandra S, Gupta S, et al. Heterogeneous conceptualization of etiopathogenesis: oral pyogenic granuloma. Natl J Maxillofac Surg 2019;10(1):3. DOI: 10.4103/njms.NJMS_55_18.

7. Khaitan T, Sinha R, Sarkar S, et al. Conservative approach in the management of oral pyogenic granuloma by sclerotherapy. J Indian Acad Oral Med Radiol 2018;30(1):46-51. DOI: 10.4103/jiaomr. jiaomr_15_18.

8. Rai S, Kaur M, Bhatnagar P. Laser: a powerful tool for treatment of pyogenic granuloma. J Cutan Aesthet Surg 2011;4(2):144-147. DOI: 10.4103/0974-2077.85044.

9. Debnath K, Chatterjee A. Management of recurrent pyogenic granuloma with platelet-rich fibrin membrane. J Indian Soc Periodontol 2018;22(4):360-364. DOI: 10.4103/jisp.jisp_86_18.

10. Gugnani S, Kawatra S. Surgical management of pyogenic granuloma: case report and review of literature. Int J Oral Health Med Res 2017;3(6):98-100.

11. Jain G, Arora R, Sharma A, et al. Irritation fibroma: report of a case. J Curr Res Sci Med 2017;3(2):118-121.DOI: 10.4103/jcrsm.jcrsm_53_17.

12. Scully C. Oral Medicine and Pathology at a Glance. Wiley Blackwell 1st ed., 2010. 
13. Parkavi A, Baburaj MD, Pimpale $S$, et al. Irritational fibroma: a case report. Acta Scient Dental Sci 2018;2(10):68-72.

14. Tandon PN, Gupta SK, Gupta DS, et al. Peripheral giant cell granuloma. Contemp Clin Dent. 2012;3(Suppl 1):S118-S121. DOI: 10.4103/0976237X.95121.

15. Mohan RP, Verma S, Singh U, et al. Epulis fissuratum: consequence of ill-fitting prosthesis. BMJ Case Rep 2013;2013(jul17 1). DOI: 10.1136/ bcr-2013-200054.

16. Tamarit-Borrás M, Delgado-Molina E, Berini-Aytés L. Removal of hyperplastic lesions of the oral cavity. A retrospective study of 128 cases. Med Oral Patol Oral Cir Bucal 2005;10(2):151-162.

17. Mortazavi $H$, Khalighi HR, Jafari $S$, et al. Epulis fissuratum in the soft palate: report of a case in a very rare location. Dent Hypotheses 2016;7(2):67-69. DOI: 10.4103/2155-8213.183798.

18. Regezi JA, Sciubba JJ, Jordan R. Oral pathology: clinical pathological correlations. 5th ed., Saunders; 2008.
19. Hasnaoui JS, Stri Z, Chkoura A, et al. Key steps to optimize management of epulis fissuratum induced by a total denture: a case report. Asian Pac J Health Sci 2017;4(3):213-219. DOI: 10.21276/apjhs.2017.4.3.32.

20. Patil KP, Kalele KP, Kanakdande VD. Peripheral giant cell granuloma: a comprehensive review of an ambiguous lesion. J Int Clin Dent Res Organ 2014;6(2):118-125. DOI: 10.4103/2231-0754.143501.

21. Sebastian. AA. Peripheral giant cell granuloma manifestation of pregnancy -report of a case. Inter J Appl Dent Sci 2016;2(2):93-95.

22. Shadman N, Ebrahimi SF, Jafari S, et al. Peripheral giant cell granuloma: a review of 123 cases. Dent Res J (Isfahan) 2009;6(1):47-50.

23. Abu Gharbyah AZ, Assaf M. Management of a peripheral giant cell granuloma in the esthetic area of upper jaw: a case report. Int J Surg Case Rep 2014;5(11):779-782. DOI: 10.1016/j.ijscr.2014.09.014.

24. Mortazavi H, Safi Y, Baharvand M, et al. Peripheral exophytic oral lesions: a clinical decision tree. Int J Dent 2017;2017:9193831. DOI: 10.1155/2017/9193831. 